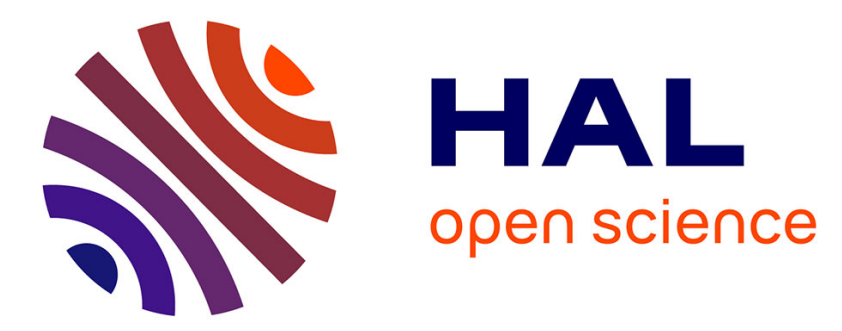

\title{
Finite element modelling of forging and other metal forming processes
}

Jean-Loup Chenot, Lionel Fourment, Richard Ducloux, Etienne Wey

\section{To cite this version:}

Jean-Loup Chenot, Lionel Fourment, Richard Ducloux, Etienne Wey. Finite element modelling of forging and other metal forming processes. 13th ESAFORM Conference on Material Forming, Apr 2010, Brescia, Italy. pp.Pages 359-362, 10.1007/s12289-010-0781-5 . hal-00573831

HAL Id: hal-00573831

https://hal-mines-paristech.archives-ouvertes.fr/hal-00573831

Submitted on 14 Aug 2013

HAL is a multi-disciplinary open access archive for the deposit and dissemination of scientific research documents, whether they are published or not. The documents may come from teaching and research institutions in France or abroad, or from public or private research centers.
L'archive ouverte pluridisciplinaire HAL, est destinée au dépôt et à la diffusion de documents scientifiques de niveau recherche, publiés ou non, émanant des établissements d'enseignement et de recherche français ou étrangers, des laboratoires publics ou privés. 


\title{
FINITE ELEMENT MODELLING OF FORGING AND OTHER METAL FORMING PROCESSES
}

\author{
J-L Chenot ${ }^{1}$, L. Fourment ${ }^{1}$, R. Ducloux ${ }^{2}$ and E. Wey ${ }^{2}$. \\ ${ }^{1}$ CEMEF, Mines ParisTech and CNRS UMR7635, B. P. 207 - F-06 904 Sophia-Antipolis, France \\ ${ }^{2}$ Transvalor S. A., 694, av. du Dr. Maurice Donat, 06255 Mougins Cedex, France
}

\begin{abstract}
The fundamental mechanical formulation is recalled for simulation of metal forming processes. The basic principles of 3-dimensional finite element discretization and of time integration are summarized. Several important numerical developments for efficient computation of large plastic deformation are briefly described. Various fields of applications to real processes are reviewed. Illustrative examples are mentioned to show the utilization of the commercial computer code Forge3 in industry, as a very flexible tool to design metal forming sequences.
\end{abstract}

KEYWORDS: Metal, Plasticity, Finite Element, Numerical Simulation, Industrial Forming Processes.

\section{HISTORICAL INTRODUCTION}

The first attempts to simulate large plastic deformations started in the 70's with two dimensional approximations, but applications were scarce due to the limited performance of computers [1-3]. Several threedimensional computations were performed at the research level in the 80's [4], but it is only in the 90's that real industrial examples could be run $[5,6]$ and at the end of 90 that it begun to be used in industry. Since 2000 many improvements have made computations faster and more accurate and now the possibility of process optimization can be achieved.

\section{MECHANICAL BASIS}

For a much more detailed account of the theoretical background, the reader is referred to [7].

\subsection{CONSTITUTIVE EQUATIONS}

The mechanical law that is often used in metal forming is isotropic elastic viscoplastic with an additive decomposition of the strain rate and a power law:

$$
\begin{gathered}
\dot{\varepsilon}=\dot{\varepsilon}^{\mathrm{e}}+\dot{\varepsilon}^{\mathrm{p}} \\
\frac{\mathrm{d}_{\mathrm{J}} \sigma}{\mathrm{dt}}=\lambda \operatorname{tr}\left(\dot{\varepsilon}^{\mathrm{e}}\right)+2 \mu \dot{\varepsilon}^{\mathrm{e}} \\
\dot{\boldsymbol{\varepsilon}}^{p}=1 / K\langle(\bar{\sigma}-R) / K\rangle^{\frac{1}{m}-1} \boldsymbol{\sigma}^{\prime}
\end{gathered}
$$

Where $\dot{\varepsilon}^{\mathrm{e}}$ is the elastic strain rate, $\dot{\varepsilon}^{\mathrm{p}}$ the plastic or visco plastic component, $\mathrm{d}_{\mathrm{J}} / \mathrm{dt}$ is for the Jauman derivative, $\lambda$ and $\mu$ are the Lamé coefficients, $\sigma$ ' is deviatoric stress tensor, $\bar{\sigma}$ is the usual equivalent stress, $\mathrm{K}$ is the consistency and mis the strain rate sensitivity.

More general material behaviour can be used:

- Temperature dependant laws,

- Anisotropic equation (Hill),

- Anisotropic kinematic hardening is defined in term of the backstress $\mathrm{X}$ and the fourth rank tensor $\mathrm{H}$ :

$$
\bar{\sigma}=\sqrt{\left(\sigma^{\prime}-\mathrm{X}\right) \mathrm{H}\left(\sigma^{\prime}-\mathrm{X}\right)}
$$

The evolution of $\mathrm{X}$ is governed by the hardening function $\mathrm{R}$ and the parameter $\beta$ :

$$
\dot{\mathrm{X}}=2 / 3 \beta(\partial \mathrm{R} / \partial \bar{\varepsilon}) \dot{\varepsilon}
$$

\subsection{CONTACT AND FRICTION}

Several important conditions must be taken into account: - unilateral contact with friction, between the work-piece and rigid tools, modelled by e. g. a generalized Coulomb law:

$$
\tau=-\mu\left(-\sigma_{\mathrm{n}}\right) \Delta \mathrm{v} /|\Delta \mathrm{v}|
$$

Where $\sigma_{\mathrm{n}}$ is the normal stress and $\Delta \mathrm{v}$ the velocity difference between tool and part.

contact between deformable bodies by a penalty approach.

\subsection{INTEGRAL FORMULATON}

For an incompressible, or quasi incompressible flow, it is desirable to utilize a mixed formulation. In the domain $\Omega$ of the part, this formulation is written for any virtual velocity and pressure fields $v^{*}, p^{*}$ as:

\footnotetext{
* Corresponding author: Mines ParisTech, B. P. 207 - F-06 904 Sophia-Antipolis, France - jean-loup.chenot@ mines-paristech.fr
} 


$$
\begin{gathered}
\int_{\Omega} \sigma^{\prime}: \dot{\varepsilon} * \mathrm{dV}-\int_{\Omega} \operatorname{pdiv}\left(\mathrm{v}^{*}\right) \mathrm{dV}-\int_{\partial \Omega_{\mathrm{c}}} \tau \mathrm{V} * \mathrm{dS}=0 \\
-\int_{\Omega}(\kappa \operatorname{div}(v)+\dot{p}) p^{*} d V=0
\end{gathered}
$$

\subsection{THERMAL COUPLING}

During heating of the preform, followed by hot forming, cooling and heat treatments of the part, it is necessary to introduce thermal and mechanical coupling. The classical heat equation for deformable bodies is written simply:

$$
\rho c \frac{d T}{d t}=\operatorname{div}(\operatorname{kgrad}(T))+f_{w}(\sqrt{3} \dot{\bar{\varepsilon}})^{m+1}
$$

where the last term is a fraction $f_{w}$ of the viscoplastic heat dissipation. The constitutive law depends on temperature. For example we have the equations:

$$
\mathrm{K}=\mathrm{K}_{0}\left(\varepsilon_{0}+\bar{\varepsilon}\right)^{\mathrm{n}} \exp (\beta / \mathrm{T}), \quad \mathrm{m}=\mathrm{m}_{0}+\mathrm{m}_{1} \mathrm{~T}
$$

The radiation condition on the free surface $\partial \Omega_{\mathrm{s}}$ is written:

$$
-\mathrm{k} \frac{\partial \mathrm{T}}{\partial \mathrm{n}}=\varepsilon_{\mathrm{r}} \sigma_{\mathrm{r}}\left(\mathrm{T}^{4}-\mathrm{T}_{0}^{4}\right)
$$

where: $\varepsilon_{\mathrm{r}}$ is the emissivity parameter, $\sigma_{\mathrm{r}}$ the Stefan constant and $\mathrm{T}_{\mathrm{O}}$ the outside temperature.

\section{NUMERICAL METHODS}

\subsection{FINITE ELEMENT DISCRETIZATION}

To-day a satisfactory compromise is based on a mixed velocity and pressure formulation using tetrahedral elements, and a bubble function for the velocity field, in order to stabilize the solution for incompressible or quasi incompressible materials. The velocity field is discretized with shape functions $\mathrm{N}_{\mathrm{n}}$, in term of nodal velocity vectors $\mathbf{V}_{\mathrm{n}}$ :

$$
\mathbf{v}=\sum_{\mathrm{n}} \mathbf{V}_{\mathrm{n}} \mathrm{N}_{\mathrm{n}}(\boldsymbol{\xi})
$$

Using isoparametric elements the mapping between the physical space with coordinates $\mathbf{x}$ and the reference space, with coordinate $\xi$ is:

$$
\mathbf{x}=\sum_{\mathrm{n}} \mathbf{X}_{\mathrm{n}} \mathrm{N}_{\mathrm{n}}(\boldsymbol{\xi})
$$

The strain rate tensor can be computed with the help of the conventional $\mathbf{B}$ descritized linear operator:

$$
\dot{\boldsymbol{\varepsilon}}=\sum_{\mathrm{n}} \mathbf{V}_{\mathrm{n}} \mathbf{B}_{\mathrm{n}}
$$

The discretized mixed integral formulation for the mechanical problem is expressed in term of the deviatoric stress increment $\Delta \sigma^{\prime}$ and pressure increment $\Delta \mathrm{p}$ :

$$
\begin{aligned}
\mathrm{R}_{\mathrm{n}}^{\mathrm{U}}=\int_{\Omega}\left(\sigma^{\prime}+\Delta \sigma^{\prime}\right) & : \mathrm{B}_{\mathrm{n}} \mathrm{dV}-\int_{\Omega}(\mathrm{p}+\Delta \mathrm{p}) \operatorname{trace}\left(\mathrm{B}_{\mathrm{n}}\right) \mathrm{dV} \\
& +\int_{\partial \Omega_{\mathrm{c}}} \mu\left(-\sigma_{\mathrm{n}}\right)(\Delta \mathrm{v} /|\Delta \mathrm{v}|) \mathrm{N}_{\mathrm{n}} \mathrm{d} \mathrm{S}=0
\end{aligned}
$$

And the discretized mass conservation:

$$
\mathrm{R}_{\mathrm{m}}^{\mathrm{P}}=\int_{\Omega}(\kappa \Delta \mathrm{t} \operatorname{div}(\mathrm{v})+\Delta \mathrm{p}) \mathrm{M}_{\mathrm{m}} \mathrm{dV}=0
$$

\subsection{TIME DISCRETIZATION}

The most widely used integration method for the velocity formulation still remains the simple Euler one step scheme. It is similar to the incremental displacement approach where the displacement is written: $\Delta \mathrm{u}=\mathrm{v} \Delta \mathrm{t}$.

It generally observed that a two levels Runge and Kutta method leads to a considerable improvement of the solution, which is particularly desirable when the workpiece undergoes very large rotations, such as in ring rolling.

\subsection{CONTACT AND MULTI BODY COUPLING}

Contact between tools and part or between several deformable materials can be imposed at the node level or with a surface approach. The so-called master and slave method is popular, but in order to avoid penetration between antagonists, there is a need for a more symmetrical formulation when the materials have similar hardness (see [8]). When the contact zone is reduced with respect to the component size, more accurate formulations are required and significant improvements can be brought by smoothing the discretized surface of the obstacle by using higher order interpolations [9].

\subsection{MESHING, REMESHING AND ADAPTIVITY}

Automatic dynamic remeshing during the simulation of the whole forming process is almost always necessary, as elements undergo very high strain which could be at the origin of degeneracy. Before this catastrophic event, decrease of element quality must be evaluated and a remeshing module must be launched periodically to recover a satisfactory element quality. The global mesh can be completely regenerated, using a Delaunay or any front tracing method, but the method of iterative improvement of the mesh, with a possible local change of element structure and connectivity, seems to be much more effective.

In order to avoid the necessity for the user to perform several computations, with different meshes to check the accuracy, an error estimation can be developed using for example the generalization of the method proposed by Zienckiewicz and Zhu. Then, if the rate of convergence of the computation is known, the local mesh refinement necessary to achieve a prescribed tolerance can be 
computed, and the meshing modules are improved to be able to respect the refinement when generating the new mesh (see [10]), or the achieve the best accuracy for a given maximum nodes number.

\subsection{ITERATIVE AND PARALLEL SOLVING}

For industrial, complicated applications with short delays, the computing time can be decreased dramatically using several or several tens of processors. This requires to use an iterative solver and to define a partition of the domain, each sub domain being associated with a processor. But the parallelization is made more complex due to remeshing and the remeshing process itself must be parallelized.

\subsection{BIMESH METHOD}

In order to reduce substantially the very long computational time required for the simulation of incremental processes such as cogging or ring rolling, a Bimesh method was developed [11]. It consists in using different finite element meshes for the resolution of the different physical problems: a main fine mesh to store the results and to carry out the thermal computations, and an intermediate coarser mesh for the mechanical calculations. It makes it possible to take advantage of the localised deformations that characterize incremental processes to coarsen the mechanical mesh and consequently reduce the computational time.

\subsection{MULTI GRID METHODS}

In the multi grid method the principle is different: several grids of different refinement are defined, but the objective is to compute the solution on the finest one. This is achieved iteratively by using different operators: smoothing, restriction and extension, which allow us to compute the solution faster than with conventional iterative methods. The effectiveness of the method was demonstrated on forging in [12].

\section{APPLICATIONS}

\subsection{COMPLEX FORGING}

The computer code Forge 3 is now designed to control numerical accuracy with the possibility of error estimation and adaptive refinement [5,10]. A mechanical and coupled thermal analysis takes into account the elasticity of the tools, the heat conduction and possibly the elastic yielding of the forging press. It is also possible to simulate several operations, including heat treatments, by transferring automatically the results from one sequence to the next one.

\subsection{DRAWING, ROLLING}

In such processes, the deformation zone is localized. When an incremental approach is preferred in order to determine the beginning of the process and the free surface when the steady state is reached, an ALE method is used to avoid complete remeshing at every step. Applications are shown in [13].

\subsection{RING ROLLING}

Ring rolling is a complex process which is considered as incremental and which exhibits very large rotations. Several approaches were tested to avoid excessive numerical inaccuracy during the large number of rotations of the work-piece, including use of second order time integration and more recently the use of a polar coordinates and an improved scheme for local contact [9].

\subsection{FLOW FORMING}

Flow Forming is a 3-dimensional process for producing axisymmetric tubular parts. The preform is attached to a rotating mandrel, rollers apply a localised action on the wall of the part, the material of which is moved along the axial direction. Using a Lagrange - Euler development, the process can be simulated with Forge 3 in order to predict possible geometric defects and the final microstructure [14].

\subsection{MECHANICAL ASSEMBLY}

The typical mechanical assembly process is riveting and it involves for example the interaction of two tools and three deformable bodies: the rivet and two sheets. In this case a robust multi body contact algorithm must be used (see for example $[7,8]$ ) in order to simulate accurately the fastening stage. Moreover if one is interested in testing the strength of the joint it is compulsory to introduce the weakening due to damage, not only during a tension test but during the riveting process itself [15].

\subsection{MACHINING}

Machining is a complex process that can be analyzed at difference scales. When the formation of the chip and the tool duration are the main objective, a numerical model can be utilized to predict the distribution of strain, strain rate and temperature in the vicinity of the tip. This approach will allow us to predict the possible formation of an adiabatic shear band (see for example [16]) and ultimately to optimize the tool geometry.

\subsection{PROCESS OPTIMIZATION}

Most often process optimization is performed in industry by trial and error, using the experience of the engineers or of the technicians. Due to the progress in computer technology, and with improved software, now available in Forge 3, it is possible to achieve process optimization, for example in forging, using only process initial data and material behaviour. The optimization is developed in order to design the best tool shape and to prevent defect during forming, as it shown in [17-18]. 


\section{CONCLUSIONS}

We have briefly shown that with the Forge 3 simulation code, a very large variety of metal forming processes can be treated and optimized. New applications appear each year and the computer code is developed continuously to include new modules for existing or new processes and also to improve the accuracy of the results and to accelerate the computations. It is expected that in the very near future, the software will allow the user to predict final local properties in the work-piece and evaluate the in service durability of the parts and components.

\section{REFERENCES}

[1] Zienkiewicz O. C., Valliapan S., King I. P., Elastosolution of engineering problems: initial stress, finite element approach, Int. J. Num. Meth. Eng., 75-100, 1, 1969

[2] Lee C. H., Kobayashi S., New solutions to rigid plastic deformation problems using a matrix method, Trans. ASME, J. Eng. Ind., 865, 95, 1973

[3] Cornfield G. C., Johnson R. H., Theoretical prediction of plastic flow in hot rolling including the effect of various temperature distribution, J. Iron Steel Inst., 567, 211, 1973

[4] G. Surdon, and J.- L. Chenot, Finite element calculations of three-dimensional hot forging, International Conference on Numerical Methods in Industrial Forming Processes Numiform'86, ed. by K. Mattiasson et al., A. A. Balkema, Rotterman,287-292,1986

[5] Soyris N., Fourment L., Coupez T., Cescutti J.-P., Brachotte G., Chenot J.-L., Forging of a connecting rod: 3-D finite element calculation, Engineering Computations, 63-81, 9, 1992

[6] Chenot J.-L., Coupez T., Fourment L., Recent Progresses in Finite Element Simulation of the forging process, Computational Plasticity: Fundamentals and applications, ed. by OWEN D. R. J., ONATE E., Pineridge Press, Swansea, 13211341, 1995

[7] Wagoner R. H., Chenot J.- L., Metal forming analysis, Cambridge University Press, Cambridge, 2001

[8] Fourment L., A Quasi-symmetric formulation for contact between deformable bodies, Revue Européenne de Mécanique Numérique, 907-918, vol. 17, 5-6-7/2008, (2008)
[9] Hachani M., Fourment L.: Improved contact treatment for metal forming processes with reduced contact area. In International Conference on Computational Contact Mechanics, 2009

[10] Bousseta R., Coupez T., Fourment L., Adaptive remeshing based on a posteriori error estimation for forging simulation, Computer Method in Applied Mechanics, 2006, special issue on "Advances in Computational Metal Forming", ed. by Fourment L., Chenot J.-L., 6579-6858, vol. 195, Issues 48-49, 2006

[11] Ramadan M., Fourment L., Perchat E., A two mesh method for speeding-up incremental processes such as cogging, in proceedings of the 12th ESAFORM conference on material forming, 2009

[12] Rey B., Mocellin K., Fourment L., A node-nested Galerkin multigrid method for metal forging simulation, Computing and Visualization in Science, 17-25, 11(1), 2008

[13] Philippe S., Fourment L., Montmitonnet P., Application of the Arbitrary Lagrangian Eulerian formulation to the numerical simulation of stationary forming processes with dominant tangential material motion, Steel Research Int. 79 (2008), Special Edition Metal Forming Conference, 571-578, vol. 2, 2008

[14] Massoni E., Chenot J.-L., 3-D finite element modelling of flow forming and incremental forming, $4^{\text {th }}$ Symposium on Incremental Forming Processes 19./20.02., Aachen, 2008

[15] Bouchard P.-O., Laurent T., Tollier L., Numerical modeling of self-pierce riveting - From riveting process modelling down to structural analysis, Journal of Material Processing Technology, 290300, vol. 202, Issues 1-3, 2008

[16] Fourment L., Delalondre F. "An adaptive A.L.E. finite element formulation for the $3 \mathrm{~d}$ simulation of adiabatic shear band formation during high speed machining", $12^{\text {th }}$ CIRP on Modelling of Machining Operations, San Sebastian, Spain, May 7-8, 2009

[17] Marie S., Ducloux R., Ejday M., Massé T., Fourment L., Bobadilla C., Montmitonnet P., Optimization of a range of $2 \mathrm{D}$ and 3D bulk forming processes by a meta-model assisted evolution strategy", in 12th ESAFORM conference on material forming. Enschede, pages 27-29, 2009

[18]Ejday M., Fourment L., Meta-model assisted MultiObjective Optimization - Application to non-steady $3 \mathrm{D}$ metal forming processes, in $8^{\text {th }}$ World Congress on Structural and Multidisciplinary Optimization (WCSMO-8), pages 1-5, 2009 